\title{
Scheerens, J., Luyten, H. and Van Ravens, J. (Eds.) (2011). Perspectives on Educational Quality: Illustrative Outcomes on Primary and Secondary Schooling in the Netherlands. Dordrecht, Heidelberg, London, New York: SpringerBriefs in Education. 148 pp., ISBN: 978- 94-007-0925-6.
}

Reviewed by Žıva Kos Kecojević

Each time we are confronted with the quality concept in education, with its practices, goals, methods, etc., it inevitably becomes obvious that their realisation starts with, or rather is dependent upon, the accepted definition of quality itself. The notion of quality is, therefore, not without internal tensions. It is strongly dependent upon the relevant context, on the interests, values and believes of the stakeholders involved. However, as the present monograph shows, the relevance of the inter-dynamics between different factors and connected priorities, the organisational infrastructure in the orientation of goals, the choice of methods, developmental activities and the implementation of different approaches to educational quality should be kept in mind at all times. The latter also differ in their connections to particular national systems, as well as on the level of their realisation and relationships between particular levels of education (see Kos Kecojević \& Gaber, 2011).

In an effort to apply this, the present monograph could be read as an analysis of the contextual factors that led to the defining and building of the Systems Model of Education. This model can be simultaneously understood as a theoretical framework and guidelines in approaching the quality of education, as well as an example of practical, applied connection to the processes of quality assurance and evaluation. In terms of their theoretical as well as practical approach to quality, the constructed definition and focal points of the Systems Model were, however, in the most part originally presented in 2004 as part of UNESCO's Education for All Global Monitoring Report (see Schereens, 2004).

The first part of the monograph considers the importance of different perspectives in defining "quality" in the context of education. "When discussing the quality of education in this book there will be a strong emphasis on what is objectively measurable and practically controllable and emphasizes the importance of objectively measurable and practically controllable. Even within that inevitably reduced frame of reference there are many different perspectives" (p. 4). Attempting to establish the need for further reductionism, the authors refer to Pirsig and put further 
emphasis on "who, which subject, or which actor poses the quality question", bearing in mind different stakeholders, including national policy makers, school governors, parents, etc. (p. 4). Qualitative aspects of quality are recognised but "hard to grasp" and "not easily captured or measured". Considering the facts, the authors turn to the part of educational quality that can and will be defined in more objective ways and can be captured by the means of scientific methods, and that aims at improving quality through methods of planned change (p. 5).

As the quality of education is likely to be defined differently by different stakeholders, the Systems Model puts forward a cross section of collective interests in terms of educational results that are important for all of the parties involved (see Scheerens, 2004, p. 3). The contextual dimension is also included and gives the model flexible and broader applicability, taking into account the situational, organisational and local context. It also includes different interpretations of quality, different anchoring points, and offers a broad set of indicators. Analytically, the model strives for a "meta-framework", using an "input-process-output" logic with regard to the functioning of education and comparing different perspectives on educational quality (p. $3,5)$. In the second part of the book, the model is rendered operational through the Dutch national context on the level of primary and secondary education.

The authors consider the Systems Model as a possible approach to defining and quantifying educational quality, according to which quality is seen as a productive process in which inputs are transferred into outcomes, keeping in mind the contextual dimension.

When examining the basic framework, six ways of defining educational quality are shown. Each of them could be chosen by relevance or in an attempt to emphasise certain parts of the basic "input-process-output-context" framework and specific relationships between these components. When quality is measured solely in terms of produced output (student achievement, etc.) the results aim for productivity. According to "the productivity view", the success of the Systems Model depends on the attainment of the desired outputs/outcomes. If we examine the interrelationship between context, input and process in an attempt to find the combination that provides the best results, we are concerned with "the instrumental effectiveness view". The latter creates a clear perspective for the selection of context, input and process indicators, namely their expected effect on outcomes. By including the financial issue we move to "the efficiency perspective", which makes a further demand on the productivity and instrumental effectiveness view, considering the highest possible outcomes at the lowest possible costs. According to "the equity perspective", inputs, processes and outcomes are analysed for their equal or fair distribution. "The adaptation perspective" looks not only at the question of how to do things right, but primarily considers the question of how to do the right things, how to set objectives 
that do justice to the expectations of the stakeholders and to the requirements education is expected to meet. The last possible view presented (the authors imply that there could be more) is "the disjointed view". Compared to the previous five views, it is an alternative view, considering each element on its own. It is the simplest view, but in the evaluative sense the most arbitrary (p. 6, 7, 130). All of the perspectives can be defined at different levels of the educational system.

In addition, the first chapter offers descriptions of some further perspectives that can be used to express the notion of educational quality, especially through the elements that are relevant to the basic aspects of quality defined by the Systems Model. For example, the functional notion of quality is put forward in the sociological approach, defining quality on the level of the fulfilment of specific social functions, including qualification, selection and allocation. Further on, the notion of organisational quality is discussed in the context of the efficiency of the individual organisation and the notion of quality from the viewpoint of various stakeholders. The so-called "alternative vision" of quality is based on UNESCO's classification of quality education, which considers individual educational traditions that are based partly on philosophical, psychological and sociological world views such as humanism, behaviourism and critical theory, and partly on pragmatic decisions based on specific contextual conditions or on a specific type of education (such as adult education, etc.).

The second chapter includes a comprehensive list of available input, process, output and context indicators. These indicators are also categorised and subjected to further elaboration using the Systems Model discussed in the first chapter. A distinction is made between achievement (learning performance), attainment (the level attained) and impact (long-term societal gains from the first two) outcomes.

Chapter three provides an insight into the Dutch schooling system. The latter is strongly classified into many relatively separate categories and subcategories of schools. Schooling is compulsory from the age of five to sixteen. A prominent feature of the system is freedom of education and the freedom to found schools, to organise the teaching in schools, as well as to determine freedom of conviction. Schools thereby differ according to ideological, educational and religious beliefs, but are also free to determine what is taught and how, and are given a choice of textbooks. More than two thirds of schools in the Netherlands are private schools, which, like public schools, are dependent on the government with regard to funding. Some older quality evaluations of the Dutch schooling system were relatively critical; despite high achievements in international studies (e.g., PISA, TIMSS, etc.), the highly stratified system appeared to be an obstacle regarding the attainment issue, especially for students with lower SES.

The fourth chapter attempts to make the most comprehensive possible 
analysis of the Dutch educational system on the level of primary and secondary schooling. The focus of the analysis is in the most part based on the relationship between achievement and attainment in the aspect of equity.

In chapter five, attention is focused on the selectivity and vocational orientation of education systems, as two of the specific aspects of quality that are highly interrelated. Examples are given of how different educational paradigms deal with the needs and demands of the labour market through the realisation of professional competence. The authors highlight two dominant paradigms that differ in terms of the age at which comprehensive education ends and vocational and academic education begins. The problem of defining indicators of selectivity and vocational orientation is one of the problems discussed. Selectivity is understood as the discrepancy between attainment and achievement, while measures for vocational orientation are made by the number of students in vocational tracks. However, some of the social implications of selectivity are also discussed. Another interesting aspect is the connection of achievement and attainment regarding economic growth. Consensus on the importance of each factor, and both combined, has not yet been reached. Furthermore, in a relatively short period of time, from 2004 to 2010, many conflicting theories have been proposed regarding the subject, some of them even by the same authors. The diversity of views on the economic benefit of selectivity of education opens a variety of possible discussions, partly because it has not been a subject of investigation until now.

Chapter six sums up the facts and findings.

The reviewed monograph provides an important insight into the rationalisation and systematisation of approaches to the quality of education. As an example of practice, it could be implemented in some individual practices of quality assurance and evaluation on the level of different national systems. Among other contributions, it offers the reader a chance to reconsider the range and limits of individual attempts and capabilities to solve and define specific issues in light of many approaches to quality. Attempts to define and implement individual views and approaches to quality should be made with reference to the notion of their sensitivity towards and capacity for perceiving and prioritising problems.

\section{References}

Kos Kecojević, Ž., \& Gaber, S. (2011). Kakovost v šolstvu v Sloveniji [Quality in Schooling in Slovenia]. Ljubljana: Faculty of Education.

Scheerens, J. (2004). The quality of education at the beginning of the 21st century. Paper for the UNESCO Education for All Global Monitoring Report. 